\title{
Are Allogeneic Blood Transfusions Associated With Decreased Survival After Surgery for Long-bone Metastatic Fractures?
}

\author{
Stein J. Janssen MD, Yvonne Braun MD, John E. Ready MD, \\ Kevin A. Raskin MD, Marco L. Ferrone MD, Francis J. Hornicek MD, MS, PhD, \\ Joseph H. Schwab MD, MS
}

Received: 23 September 2014/ Accepted: 21 January 2015/Published online: 31 January 2015

(C) The Association of Bone and Joint Surgeons \& 2015

\begin{abstract}
Background Previous studies have shown that perioperative blood transfusion increases cancer recurrence and decreases patient survival after resection of primary malignancies. The question arises whether this association also exists in patients with already disseminated disease undergoing surgery for metastatic long-bone fractures.

Purposes We sought to determine whether perioperative allogeneic blood transfusion is associated with decreased survival after operative treatment of long-bone metastatic

One of the authors (SJ) received funding, an amount less than USD 10,000, from the Anna Foundation (Oegstgeest, The Netherlands) and an amount less than USD10,000, from the Michael van Vloten Foundation (Rotterdam, The Netherlands). One author (JS) certifies that he or a member of his family has or may receive payments or benefits, an amount less than USD 10,000, from Stryker (Kalamazoo, MI, USA), and an amount less than USD 10,000, from Biom'up (Saint-Priest, Lyon, France).

All ICMJE Conflict of Interest Forms for authors and Clinical Orthopaedics and Related Research editors and board members are on file with the publication and can be viewed on request.

Each author certifies that his or her institution approved or waived approval for the human protocol for this investigation and that all investigations were conducted in conformity with ethical principles of research.

This work was performed at Massachusetts General Hospital, Boston, MA, USA.
\end{abstract}

Electronic supplementary material The online version of this article (doi:10.1007/s11999-015-4167-3) contains supplementary material, which is available to authorized users.

S. J. Janssen ( $ه)$, Y. Braun, K. A. Raskin,

F. J. Hornicek, J. H. Schwab

Department of Orthopaedic Surgery, Orthopaedic Oncology

Service, Massachusetts General Hospital - Harvard Medical

School, Room 3.946, Yawkey Building, 55 Fruit Street, Boston,

MA 02114, USA

e-mail: steinjanssen@gmail.com fractures after accounting for clinical, laboratory, and treatment factors. Secondarily, we aimed to identify potential factors that are associated with decreased survival.

Methods We included 789 patients in our retrospective study who underwent surgery at two institutions for a pathologic or impending metastatic long-bone fracture. We used multivariable Cox proportional hazards regression model analysis to assess the relationship of perioperative allogeneic blood transfusion with survival, and accounted for patient age, sex, comorbidities, BMI, tumor type, fracture type and location, presence of other bone and visceral metastases, previous radiotherapy and systemic therapy, preoperative embolization, preoperative hemoglobin level, treatment type, anesthesia time, blood loss, duration of hospital admission, year of surgery, and hospital.

Results Considering transfusion as an "exposure," and comparing patients who received transfusions with those who did not, we found that blood transfusion was not associated with decreased survival after accounting for all explanatory variables (hazard ratio [HR] 1.06; 95\% CI, $0.87-1.30 ; \mathrm{p}=0.57)$. Evaluating transfusion in terms of dose-response, we found that patients who received more transfusions had lower survival compared with those who had fewer transfusions after accounting for all explanatory variables (HR per unit of blood transfused, 1.07; 95\% CI, $1.02-1.12 ; \mathrm{p}=0.005)$. We found that age (HR, 1.02; $95 \%$

\section{J. E. Ready, M. L. Ferrone}

Department of Orthopaedic Surgery, Orthopaedic Oncology Service, Brigham and Women's Hospital, Boston, MA, USA 
CI, 1.01-1.02; p < 0.001), comorbidity status (HR, 1.06; 95\% CI, $1.01-1.10 ; \mathrm{p}=0.014)$, duration of hospital stay (HR, 1.02; 95\% CI 1.00-1.03; $\mathrm{p}=0.021$ ), tumor type (HR, $1.71 ; 95 \% \mathrm{CI}, 1.44-2.03$; $\mathrm{p}<0.001)$, and visceral metastases (HR, 1.59; 95\% CI, 1.34-1.88; $\mathrm{p}<0.001$ ) were independently associated with survival.

Conclusion We found that exposure to perioperative allogeneic blood transfusion does not decrease survival, with the numbers available. However, our sample size might have been insufficient to reveal a small but potentially relevant effect. Our results do suggest a dose-response relationship; patients who received more transfusions had lower survival compared with those with fewer transfusions. Risk of death increased by $7 \%$ per unit of blood transfused.

Level of Evidence Level III, prognostic study.

\section{Introduction}

Perioperative allogeneic blood transfusion has been associated with tumor recurrence and decreased survival in patients with numerous primary malignancies, including colon, esophageal, hepatic, bladder, and endometrial cancers $[1,15,23,26]$. This detrimental effect of blood transfusion is explained by the immunomodulating effects of allogeneic blood transfusions [1, 15, 23, 26]. The immunomodulating effect was first hypothesized in 1973 in a study showing improved graft survival in patients who received allogeneic blood transfusion before kidney transplantation [19]. This led to the idea by Gantt in 1981 [10] that in patients with malignant tumors, blood transfusions would give the tumor "a better chance to survive". Although the exact mechanism is still unclear [4], several subsequent clinical and laboratory studies confirmed the immunosuppressive effect of blood transfusions in patients with cancer $[4,11,26]$.

Approximately $2 / 3$ of patients with metastatic breast or prostate cancer and $1 / 3$ with metastatic lung or gastrointestinal cancer have bone metastases develop [8, 17, 22]. Bone metastatic disease adversely affects quality of life and survival $[3,22]$, and many patients with bone metastases undergo surgery to treat or prevent a pathological fracture [3, 5, 22]. Blood loss during operative treatment of metastatic fractures can be substantial and blood transfusions frequently are administered [25]. Although studies suggest that transfusions increase the risk of metastasis and death $[1,15,23,26]$, we do not know whether allogeneic blood transfusions influence survival in patients with already disseminated cancer.

We therefore sought to determine whether perioperative allogeneic blood transfusion is associated with decreased patient survival after operative treatment of long-bone metastatic fractures, accounting for clinical, laboratory, and treatment factors. Secondarily, we aimed to identify potential factors associated with decreased survival.

\section{Methods}

Our retrospective study was approved by our institutional review board and a waiver of informed consent was obtained. We included all 789 eligible patients with an impending or pathological metastatic long-bone fracture undergoing surgery between 1999 and 2013 at two affiliated university medical centers. Metastatic disease included, in addition to metastases from solid organs, multiple myeloma and lymphoma; we regarded the femur, humerus, tibia, fibula, radius, and ulna as long-bones. Medical records of patients with a billing or diagnostic code for a pathological long-bone fracture or prophylactic treatment of an impending fracture were reviewed to assess eligibility (Appendix 1. Supplemental material is available with the online version of $\mathrm{CORR}^{\circledR}$ ). Exclusion criteria were: (1) revision procedures; (2) metastatic involvement of the acetabulum or pelvis requiring additional reconstruction; (3) metastatic fractures in multiple bones requiring surgery; and (4) operative treatment other than endoprosthetic reconstruction, intramedullary nailing, plate-screw fixation, and dynamic hip screw, or a combination thereof.

The decision to operate and the operative strategy were based on estimated survival, location and size of the metastatic lesion, primary tumor type, level of disability, and pain. Postoperative care and rehabilitation varied among patients owing to disease severity.

Survival was our primary outcome measure. We used the Social Security Death Index (a database of death records created from the United States Social Security Administration) throughout February 24, 2014 to establish date of death [12]. February 24, 2014 was considered the final moment of followup for assessment of the outcome. Six hundred thirty-seven patients $(81 \%)$ were deceased by the final moment of followup.

We defined perioperative allogeneic blood transfusion as transfusion of packed red blood cells within 7 days before until 7 days after surgery. Transfusion volume was expressed as the number of units transfused; one unit of blood contains approximately $330 \mathrm{~mL}$ but can vary from $300 \mathrm{~mL}$ to $360 \mathrm{~mL}$ (the hematocrit per unit of blood can vary from $55 \%$ to $58 \%$ ). Patients in the "no transfusion" group either had no perioperative transfusion or only autologous blood transfusion. We did not account for transfusion of other blood products, including fresh frozen plasma or platelets. Seventy percent (914 of 1298) of the 
packed red blood cells transfused in this study were leukoreduced (leucocytes removed from packed red blood cells). We found no difference in survival between patients who received only leukoreduced blood units $(\mathrm{n}=288)$ and patients who received at least one nonleukoreduced blood unit $(\mathrm{n}=155)(\mathrm{p}=0.68$, by log-rank analysis). Transfusion guidelines in both hospitals did not change during our study period. The blood transfusion threshold guidelines at one hospital (Hospital 1) during the 15-year study period were: hematocrit less than $24 \%$ for patients younger than 40 years; less than $27 \%$ for patients between 40 and 60 years old; and less than $30 \%$ for patients 60 years or older. At the other hospital (Hospital 2), the hematocrit thresholds used were: $26 \%$ for patients with cancer, who were pregnant, or who had preoperative anemia; $30 \%$ for patients with acute coronary syndrome or major thoracic surgery; and $21 \%$ for patients who were normovolemic and nonbleeding for which the previously mentioned thresholds did not apply. Adherence to these transfusion guidelines was not documented; however, we assessed the trigger for transfusion with time and graphed pretransfusion hematocrit levels (Fig. 1). Linear regression analysis showed no change in patient hematocrit level resulting in transfusion with time $(\mathrm{p}=0.12)$.

We measured the following explanatory patient variables: age at time of surgery, sex, comorbidity status, BMI in $\mathrm{kg} / \mathrm{m}^{2}$, primary tumor type, fracture type, fracture location, presence of other bone metastatic lesions, presence of visceral metastases, previous local radiotherapy, previous systemic therapy, preoperative embolization of the tumor, preoperative hemoglobin level, operative treatment type, anesthesia time in minutes, total estimated blood loss during surgery in $\mathrm{mL}$, duration of hospital admission in days, year of surgery, and hospital (1 or 2).

Patient comorbidity status was assessed using the modified Charlson Comorbidity Index [6, 20], which provides a score ranging from 0 to 24 , with a higher score representing more severe comorbidity status, based on 12 weighted comorbidities [20]. We determined the modified Charlson Comorbidity Index through a previously described algorithm based on International Classification of Diseases, $9^{\text {th }}$ revision (ICD9) codes given to the patient before the day of surgery (Appendix 2. Supplemental material is available with the online version of $\mathrm{CORR}^{\circledR}$ ) $[9,21,24]$.

Based on the existing literature, we categorized primary tumor type into relatively good prognosis (breast, kidney, prostate, thyroid, myeloma, and lymphoma) and poor prognosis (all other tumor types) [2, 13, 18].

Fracture type was impending or pathological. Impending fractures were defined as a destructive bone lesion with no visible fracture line, loss of height, rotation, or angulation. The degree of destruction and intractable pain did mandate,

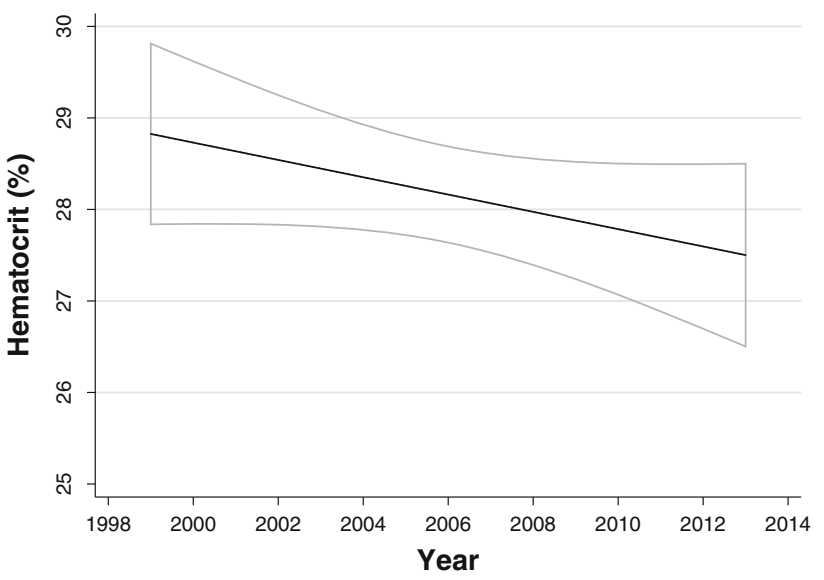

Fig. 1 The change in hematocrit level triggering perioperative allogeneic blood transfusion in our cohort with time is shown. The decrease was not significant as assessed using linear regression analysis $(\mathrm{p}=0.12)$. The $95 \% \mathrm{CIs}$ are indicated in gray. The hematocrit to hemoglobin ratio was approximately $3: 1$.

in the surgeon's opinion, operative treatment to preclude a pathological fracture.

We extracted the presence of other bone metastatic lesions from bone scans, CT scans, and other imaging reports, and categorized combined results into either multiple- or single-bone metastatic lesion(s). The presence of visceral metastases was derived from $\mathrm{CT}$ and positron emission tomography reports. We regarded lung, liver, and brain metastases as visceral metastases.

We defined previous local radiotherapy as radiotherapy to the area of surgery, and previous systemic therapy as any type of hormonal therapy, immunotherapy, or chemotherapy for the primary tumor.

Preoperative embolization was performed in 21 cases, of which most were renal cell carcinomas (15 of 20 [75\%]), to reduce tumor vascularity and decrease intraoperative blood loss.

Preoperative hemoglobin was extracted when measured within 7 days before surgery; we used the last available hemoglobin measurement before surgery.

Types of operative treatment were endoprosthetic reconstruction, intramedullary nailing, plate-screw fixation, or dynamic hip screw.

We considered anesthesia time as a surrogate marker for operative treatment time and measured this time in minutes from the moment the patient entered the operating room until the patient left the operating room.

\section{Statistical Analysis}

Variables are presented as frequencies with percentages for categoric variables and median with interquartile range (IQR) for continuous variables. 
Table 1. Patient- and treatment characteristics for no transfusion group and allogeneic transfusion group $(\mathrm{n}=789)$

\begin{tabular}{|c|c|c|c|}
\hline Variable & $\begin{array}{l}\text { No transfusion (no exposure) }(n=346) \\
\text { Median (interquartile range) }\end{array}$ & $\begin{array}{l}\text { Perioperative allogeneic blood } \\
\text { transfusion* (exposure) }(\mathrm{n}=443) \\
\text { Median (interquartile range) }\end{array}$ & $\mathrm{p}$ value \\
\hline Age (years) & $62(53-70)$ & $64(55-73)$ & $0.025^{\S}$ \\
\hline Modified Charlson Comorbidity Index & $6(6-7)$ & $6(6-8)$ & $<0.001^{\S}$ \\
\hline Preoperative hemoglobin level $\left(\mathrm{g} / \mathrm{dL}^{\dagger}\right)$ & $12(11-13)$ & $11(10-12)$ & $<0.001^{\S}$ \\
\hline Total estimated blood loss during surgery $\left(\mathrm{mL}^{\dagger}\right)$ & $200(100-300)$ & $300(150-500)$ & $<0.001^{\S}$ \\
\hline Anesthesia time (minutes ${ }^{\dagger}$ ) & $185(153-220)$ & $198(165-236)$ & $<0.001^{\S}$ \\
\hline Duration of hospital admission (days) & $5(3-7)$ & $7(5-11)$ & $<0.001^{\S}$ \\
\hline \multirow{2}{*}{$\mathrm{BMI}\left(\mathrm{kg} / \mathrm{m}^{2}\right)^{\dagger}$} & $27(24-31)$ & $26(22-29)$ & $<0.001^{\S}$ \\
\hline & $\mathrm{n}(\%)$ & $\mathrm{n}(\%)$ & \\
\hline \multicolumn{4}{|l|}{ Sex } \\
\hline Men & $180(51)$ & $171(49)$ & \multirow[t]{2}{*}{$<0.001^{\S}$} \\
\hline Women & $166(38)$ & $272(62)$ & \\
\hline \multicolumn{4}{|l|}{ Primary tumor type } \\
\hline Good prognosis & $186(40)$ & $281(60)$ & \multirow[t]{2}{*}{$0.007^{\S}$} \\
\hline Poor prognosis & $160(50)$ & $162(50)$ & \\
\hline \multicolumn{4}{|l|}{ Fracture type } \\
\hline Impending fracture & $178(52)$ & $163(48)$ & \multirow[t]{2}{*}{$<0.001^{\S}$} \\
\hline Pathological fracture & $168(37.5)$ & $280(62.5)$ & \\
\hline \multicolumn{4}{|l|}{ Fracture location } \\
\hline Femur & $215(37)$ & $359(63)$ & \multirow[t]{5}{*}{$<0.001^{\S}$} \\
\hline Humerus & $113(62)$ & $69(38)$ & \\
\hline Tibia & $17(61)$ & $11(39)$ & \\
\hline Radius & $0(0)$ & $3(100)$ & \\
\hline Ulna & $1(50)$ & $1(50)$ & \\
\hline \multicolumn{4}{|l|}{ Number of bone metastatic lesions } \\
\hline Single & $103(55)$ & $84(45)$ & \multirow[t]{2}{*}{$<0.001^{\S}$} \\
\hline Multiple & $243(40)$ & $359(60)$ & \\
\hline \multicolumn{4}{|l|}{ Visceral metastases } \\
\hline No & $195(47)$ & $224(53)$ & \multirow[t]{2}{*}{0.114} \\
\hline Yes (lung, liver, or brain) & $151(41)$ & $219(59)$ & \\
\hline \multicolumn{4}{|l|}{ Previous local radiotherapy } \\
\hline No & $282(44)$ & $359(56)$ & \multirow[t]{2}{*}{0.927} \\
\hline Yes & $64(43)$ & $84(57)$ & \\
\hline \multicolumn{4}{|l|}{ Previous systemic therapy } \\
\hline No & $148(49)$ & $152(51)$ & \multirow[t]{2}{*}{$0.018^{\S}$} \\
\hline Yes & $198(40)$ & $291(60)$ & \\
\hline \multicolumn{4}{|l|}{ Preoperative embolization of tumor } \\
\hline No & $338(44)$ & $431(56)$ & \multirow[t]{2}{*}{0.822} \\
\hline Yes & $8(40)$ & $12(60)$ & \\
\hline \multicolumn{4}{|l|}{ Operative treatment type } \\
\hline Intramedullary nailing & $221(47)$ & $246(53)$ & \multirow[t]{4}{*}{$<0.001^{\S}$} \\
\hline Endoprosthetic reconstruction & $55(30)$ & $129(70)$ & \\
\hline Plate-screw fixation & $61(49)$ & $63(51)$ & \\
\hline Dynamic hip screw & $9(64)$ & $5(36)$ & \\
\hline
\end{tabular}


Table 1. continued

\begin{tabular}{lccc}
\hline & $\mathrm{n}(\%)$ & $\mathrm{n}(\%)$ \\
\hline Year & & & \\
1999-2003 & $88(39)$ & $138(61)$ & 0.128 \\
$2004-2008$ & $105(43)$ & $137(57)$ \\
$2009-2013$ & $153(48)$ & $188(55)$ \\
Hospital $^{\#}$ & & $255(57)$ \\
Hospital 1 & $153(45)$ & 0.664 \\
Hospital 2 & $193(43)$ & \\
\hline
\end{tabular}

$\S \mathrm{p}<0.05$;*allogeneic blood transfusion within 7 days before until 7 days after surgery; ${ }^{\dagger}$ preoperative hemoglobin level was available for 740 patients (309 in no transfusion group, 431 in transfusion group), total estimated blood loss in 672 patients (293 in no transfusion group, 379 in transfusion group), anesthesia time for 704 patients (315 in no transfusion group, 389 in transfusion group), and BMI for 610 patients (284 in no transfusion group, 326 in transfusion group); ${ }^{*}$ primary tumor type with good prognosis includes breast, kidney, prostate, thyroid, myeloma and lymphoma and with poor prognosis includes all other tumor types; ${ }^{\text {\# }}$ see text for transfusion guidelines per hospital.

Bivariate analysis was used to compare explanatory variables between the no transfusion group (no exposure) and the perioperative allogeneic blood transfusion group (exposure) by Fisher's exact test for categoric variables and Mann-Whitney U test (also known as the rank-sum test) for continuous variables. We used nonparametric analysis for continuous variables as visual inspection of histograms suggested nonnormal distributions.

Multivariate Cox regression analysis was used to assess the relationship of perioperative allogeneic blood transfusion with survival, adjusted for all explanatory variables included in the study. We compared the exposure with the no exposure group, and assessed a dose-response relationship. Hazard ratios (HRs) - the relative likelihood of death in the exposure group versus the no exposure group and per unit of blood transfused-with $95 \%$ CIs were provided to quantify the association with survival. To preclude overfitting of the model, we reduced the number of variables by including year of surgery as a continuous variable and categorized location of the fracture into upper or lower extremity. We used multiple imputation for missing values (number of imputations was set to 40; ie, the missing values were 40 times replaced by values imputed based on all other explanatory variables): hemoglobin level was missing in 49 of $789(6.2 \%)$ cases, total estimated blood loss was missing in 117 of $789(15 \%)$ cases, anesthesia time was missing in 85 of $789(11 \%)$ cases, and BMI was missing in 179 of 789 (23\%) cases. A two-tailed $\mathrm{p}$ value less than 0.05 was considered significant; all statistical analyses were performed using Stata ${ }^{\circledR}$ 13.0 (StataCorp LP, College Station, TX, USA).

Study patients included 351 (44\%) men and $438(56 \%)$ women, with a median age of 64 years (IQR, 54-72; Table 1). Median preoperative hemoglobin was $11 \mathrm{~g} / \mathrm{dL}$ (available for 740 patients; IQR, 10-12) and median
Table 2. Origin of primary tumors $(n=789)$

\begin{tabular}{lc}
\hline Tumor distribution & Number $(\%)$ \\
\hline Lung & $191(24)$ \\
Breast & $181(23)$ \\
Myeloma & $116(15)$ \\
Kidney & $74(9.4)$ \\
Prostate & $45(5.7)$ \\
Lymphoma & $36(4.6)$ \\
Melanoma & $20(2.5)$ \\
Colorectal & $16(2.0)$ \\
Esophagus & $15(1.9)$ \\
Thyroid & $15(1.9)$ \\
Hepatocellular & $11(1.4)$ \\
Other & Unknown \\
\hline
\end{tabular}

$\uparrow$ Bladder $(n=8)$, neuroendocrine $(n=6)$, salivary gland $(n=5)$, adenocarcinoma of unknown origin $(n=5)$, pancreas $(n=4)$, ovaries $(\mathrm{n}=4)$, stomach $(\mathrm{n}=1)$, vulva $(\mathrm{n}=2)$, and endometrium $(\mathrm{n}=2)$

perioperative estimated blood loss was $200 \mathrm{~mL}$ (available for 672 patients; IQR, 100-400). There were 341 (43\%) impending and $448(57 \%)$ pathological fractures. Most fractures were in the femur (574 of 789; 73\%) and humerus (182 of $789 ; 23 \%)$. The five most common primary tumor types were lung (191 of $789 ; 24 \%$ ), breast (181 of 789 ; $23 \%$ ), myeloma (116 of $789 ; 15 \%$ ), kidney (74 of 789 ; $9.4 \%$ ), and prostate (45 of $789 ; 5.7 \%$; Table 2 ). The median number of allogeneic blood units transfused among patients (443 of 789 patients; 56\%) who received a transfusion was two (IQR, 2-4; range, 1-15). Three hundred forty-six (44\%) patients did not have a perioperative transfusion. Median overall survival was 254 days $(95 \%$ 
Table 3. Multivariate Cox regression analysis assessing the influence of perioperative allogeneic blood transfusion and the number of units transfused on survival

\begin{tabular}{|c|c|c|c|c|c|c|}
\hline & \multicolumn{3}{|c|}{ Blood transfusion (exposure/no exposure)* } & \multicolumn{3}{|c|}{ Blood transfusion (per unit transfused)* } \\
\hline & $\begin{array}{l}\text { Standard } \\
\text { error }\end{array}$ & $\begin{array}{l}\text { Hazard ratio } \\
(95 \% \mathrm{CI})\end{array}$ & $\mathrm{p}$ value & $\begin{array}{l}\text { Standard } \\
\text { error }\end{array}$ & $\begin{array}{l}\text { Hazard ratio } \\
(95 \% \mathrm{CI})\end{array}$ & $\mathrm{p}$ value \\
\hline Age (years) & 0.004 & $1.016(1.009-1.023)^{\S}$ & $<0.001^{\S}$ & 0.004 & $1.015(1.008-1.022)^{\S}$ & $<0.001^{\S}$ \\
\hline Modified Charlson Comorbidity Index & 0.024 & $1.054(1.009-1.102)^{\S}$ & $0.019^{\S}$ & 0.024 & $1.057(1.011-1.105)^{\S}$ & $0.014^{\S}$ \\
\hline Preoperative hemoglobin level $\left(\mathrm{g} / \mathrm{dL}^{\dagger}\right)$ & 0.028 & $0.937(0.884-0.994)^{\S}$ & $0.031^{\S}$ & 0.027 & $0.950(0.898-1.004)$ & 0.073 \\
\hline $\begin{array}{l}\text { Total estimated blood loss during } \\
\text { surgery }\left(\mathrm{mL}^{\dagger}\right)\end{array}$ & $<0.001$ & $1.000(1.000-1.000)$ & 0.521 & $<0.001$ & $1.000(0.999-1.000)$ & 0.175 \\
\hline Anesthesia time $\left(\right.$ minutes $\left.^{\dagger}\right)$ & $<0.001$ & $1.002(1.000-1.003)$ & 0.063 & $<0.001$ & $1.001(1.000-1.003)$ & 0.074 \\
\hline Duration of hospital admission (days) & 0.007 & $1.021(1.007-1.036)^{\S}$ & $0.003^{\S}$ & 0.008 & $1.017(1.003-1.032)^{\S}$ & $0.021^{\S}$ \\
\hline BMI $\left(\mathrm{kg} / \mathrm{m}^{2 \dagger}\right)$ & 0.009 & $0.993(0.976-1.010)$ & 0.421 & 0.009 & $0.994(0.977-1.011)$ & 0.462 \\
\hline Male sex & 0.089 & $1.035(0.874-1.225)$ & 0.690 & 0.088 & $1.044(0.884-1.232)$ & 0.612 \\
\hline Poor prognosis tumor type & 0.147 & $1.694(1.429-2.008)^{\S}$ & $<0.001^{\S}$ & 0.148 & $1.713(1.445-2.029)^{\S}$ & $<0.001^{\S}$ \\
\hline Pathological fracture & 0.095 & $1.006(0.836-1.210)$ & 0.950 & 0.093 & $0.983(0.818-1.183)$ & 0.859 \\
\hline Lower extremity & 0.108 & $0.991(0.800-1.227)$ & 0.933 & 0.104 & $0.967(0.783-1.195)$ & 0.758 \\
\hline Other bone metastatic lesions & 0.123 & $1.205(0.987-1.471)$ & 0.067 & 0.120 & $1.167(0.955-1.427)$ & 0.132 \\
\hline Visceral metastases & 0.138 & $1.584(1.334-1.880)^{\S}$ & $<0.001^{\S}$ & 0.138 & $1.586(1.337-1.882)^{\S}$ & $<0.001^{\S}$ \\
\hline Previous local radiotherapy & 0.114 & $1.094(0.892-1.341)$ & 0.389 & 0.114 & $1.097(0.895-1.345)$ & 0.371 \\
\hline Previous systemic therapy & 0.099 & $1.055(0.877-1.226)$ & 0.571 & 0.098 & $1.042(0.867-1.252)$ & 0.661 \\
\hline Preoperative embolization of tumor & 0.301 & $1.153(0.692-1.922)$ & 0.584 & 0.280 & $1.068(0.639-1.786)$ & 0.801 \\
\hline \multicolumn{7}{|l|}{ Operative treatment type } \\
\hline Intramedullary nailing & Reference value & Reference value & Reference value & Reference value & Reference value & Reference value \\
\hline Endoprosthetic reconstruction & 0.124 & $1.126(0.907-1.397)$ & 0.283 & 0.124 & $1.135(0.915-1.408)$ & 0.251 \\
\hline Plate-screw fixation & 0.145 & $1.029(0.780-1.358)$ & 0.838 & 0.142 & $1.010(0.766-1.331)$ & 0.946 \\
\hline Dynamic hip screw & 0.267 & $0.788(0.406-1.533)$ & 0.483 & 0.283 & $0.834(0.429-1.620)$ & 0.592 \\
\hline Year of surgery & 0.010 & $1.011(0.991-1.031)$ & 0.295 & 0.010 & $1.014(0.993-1.034)$ & 0.187 \\
\hline Hospital $1^{\#}$ & 0.083 & $0.859(0.711-1.038)$ & 0.115 & 0.085 & $0.881(0.729-1.064)$ & 0.187 \\
\hline $\begin{array}{l}\text { Blood transfusion* (exposure } \\
\text { versus no exposure) }\end{array}$ & 0.109 & $1.061(0.867-1.298)$ & 0.565 & - & - & - \\
\hline Blood transfusion* (per unit transfused) & - & - & - & $0.026^{\S}$ & $1.069(1.020-1.121)^{\S}$ & $0.005^{\S}$ \\
\hline
\end{tabular}

$\S \mathrm{p}<0.05$; *allogeneic blood transfusion within 7 days before until 7 days after surgery; ${ }^{\dagger}$ preoperative hemoglobin level was available in 740 patients, total estimated blood loss in 672 patients, anesthesia time in 704 patients, and BMI in 610 patients. Missing values were imputed using multiple linear imputation including all variables (the number of imputations was set to 40); "primary tumor type with good prognosis includes: breast, kidney, prostate, thyroid, myeloma and lymphoma; ${ }^{\#}$ see text for transfusion guidelines per hospital (Hospital 2 is the reference group).

CI, 221-288) and $42 \%$ of the patients survived 1 year $(331$ of 789).

Factors associated with perioperative allogeneic blood transfusion in bivariate analyses included older age $(\mathrm{p}=0.025)$, more severe comorbidity status $(\mathrm{p}<0.001)$, lower preoperative hemoglobin level $(\mathrm{p}<0.001)$, more blood loss during surgery $(\mathrm{p}<0.001)$, longer anesthesia time $(\mathrm{p}<0.001)$, longer hospital stay $(\mathrm{p}<0.001)$, lower BMI $(\mathrm{p}<0.001)$, female sex $(\mathrm{p}<0.001)$, primary tumor type with relatively good prognosis $(\mathrm{p}=0.007)$, pathological fracture $(p<0.001)$, multiple metastatic bone lesions $(\mathrm{p}<0.001)$, and previous systemic therapy ( $p=0.018$; Table 1). Furthermore, there was a difference between the no transfusion and the transfusion groups among location of the fracture $(p<0.001)$ and type of operative treatment $(\mathrm{p}<0.001$; Table 1$)$.

\section{Results}

Association of Transfusion with Survival

Considering transfusion as an exposure and comparing patients who received transfusions with those who did not, we found that blood transfusion was not associated with decreased survival after surgery of a long-bone metastasis. The HR after accounting for all explanatory variables in multivariable Cox regression analysis was 1.06 with a $95 \%$ CI of 0.87 to $1.30(\mathrm{p}=0.57)$, indicating no difference in survival between patients exposed to blood transfusions and those who were not exposed (Table 3 ).

Evaluating transfusion in terms of dose-response, we found that patients who received more transfusions during their skeletal stabilization procedures had poorer survival 
compared with those who had fewer transfusions. Multivariable Cox regression analysis showed an HR of 1.07 (95\% CI, 1.02-1.12; p = 0.0051) per unit of blood transfused after accounting for all explanatory variables, meaning a $7 \%$ higher risk of death per unit of blood transfused (Table 3).

\section{Risk Factors for Decreased Survival}

We found that older age, more severe comorbidity status, longer duration of hospital stay, poor prognosis tumor type, and visceral metastases were associated with decreased survival after accounting for likely confounding variables.

Variables independently associated with decreased survival from the multivariable Cox regression analysis including blood transfusion units as a continuous variable were: age (HR, 1.02; 95\% CI, 1.01-1.02; p < 0.001), modified Charlson Comorbidity Index (HR, 1.06; 95\% CI, 1.01-1.10; $\mathrm{p}=0.014$ ), duration of hospital stay (HR, 1.02; 95\% CI, 1.00-1.03; $\mathrm{p}=0.021)$, tumor type (HR, 1.71; 95\% CI, 1.44-2.03; $\mathrm{p}<0.001)$, and visceral metastases (HR, 1.59; 95\% CI, 1.34-1.88; $\mathrm{p}<0.001$; Table 3).

\section{Discussion}

Perioperative blood transfusion increases cancer recurrence and decreases patient survival after resection of primary malignancies $[1,15,23,26]$. It is unclear if the same is true for patients with cancer already disseminated to bone. After controlling for likely confounding variables, we found that exposure to perioperative allogeneic blood transfusion was not associated with decreased survival in patients undergoing surgery for metastatic fractures. However, when evaluating a dose-response relationship, we found that patients who received more transfusions had lower survival compared with those with fewer transfusions. Risk of death increased by $7 \%$ per unit of blood transfused.

Our study has several limitations. First, with our sample size we found no effect of exposure to blood transfusion on survival; however, a larger sample size might have resulted in a significant difference in survival between patients exposed to blood transfusions and those not exposed. To achieve a power of 0.80 and assuming a similar HR, variability, and covariate correlation, we would have needed 17,058 patients to show a difference in survival between the patients who had blood transfusion and those who did not (with alpha of 0.05). With the current sample size, variability, and covariate correlation, we would have found a difference in survival between the transfusion group and no transfusion group when the hazard ratio exceeded 1.31 (alpha of 0.05 and power of 0.80 ). The relatively small sample size is a limitation as even a small effect would be clinically relevant; a large sample size might have revealed such a small effect. Second, there were no uniform criteria for operative treatment owing to the retrospective design of the study; however, we see this as a minor limitation as most surgeons used similar approaches during the study period when deciding whether to stabilize a pathological fracture or intervene in the face of an impending fracture. In general, a pathological fracture was stabilized when the patient was expected to live longer than 30 days. An impending fracture was treated surgically when there was pain on loadbearing or in case of substantial bone destruction in a loadbearing bone. Third, although transfusion guidelines did not change during our study period, the exact indication in every patient was not documented; however, we believe this is a minor limitation as we found no change in the hematocrit level during the time that was associated with transfusion. Fourth, we assessed overall and not cancer-specific survival. We could not determine how many of the patients had died from their malignancy as opposed to from other causes; however, as the majority of patients who have skeletal metastases eventually die from their malignancies, we do not believe this is a severe limitation.

We found that allogeneic blood transfusion did not affect survival of patients undergoing surgery for metastatic long-bone fractures with the numbers available. Clausen et al. [7] showed that perioperative allogeneic blood transfusion in patients with spine metastases was not associated with 3-month survival; they found an increased 12-month survival after 1 to 2 units of allogeneic blood transfusion compared with no transfusion (odds ratio, 2.6; 95\% CI, 1.0-6.8; $\mathrm{p}=0.049$ ) [7]. Increased survival might be explained by a difference in indication for blood transfusion or anatomic site studied, or because of the few confounding factors taken into account (preoperative hemoglobin, age, sex, Tokuhashi score [survival prognostication score], and number of instrumented levels) [7]. Previous studies in visceral metastatic disease have shown a negative effect of perioperative blood transfusion on survival $[14,16]$ : Katoh et al. [14] found that perioperative transfusion was independently associated with worse survival after resection of stage IV (disseminated disease) colorectal cancer $(\mathrm{n}=162)$ after accounting for clinical and treatment parameters; Margulis et al. [16] reported that survival of patients undergoing cytoreductive nephrectomy for metastatic renal cell carcinoma also was negatively influenced by intraoperative blood transfusion. The decrease in observed survival after perioperative blood transfusions in primary malignancies was not apparent in our study on metastatic long-bone fractures and might be explained by 
the already widely disseminated disease and poor overall survival, potentially attenuating the effect of blood transfusions.

We found that older age, more severe comorbidity status, longer duration of hospital stay, poor prognosis tumor type, and visceral metastases were associated with decreased patient survival. Results from previous studies support the association of tumor type and visceral metastases with survival [2, 13, 18]. Bauer and Wedin [2] reported a survival rate of 0.30 at 1 year in a retrospective cohort of 241 patients who had surgery for bone metastatic disease; they found decreased survival among patients with a pathological fracture, visceral metastases, multiple bone metastases, and lung cancer. Katagiri et al. [13] reported a survival rate of 0.48 at 1 year in a retrospective cohort of 350 patients with bone metastatic disease. Poor performance status, specific tumor types (hepatocellular, gastric, and lung carcinoma), visceral metastases, previous chemotherapy, and multiple skeletal metastases were risk factors for decreased patient survival. A prospective cohort study by Nathan et al. [18] showed a median survival of 8 months for 191 patients who had surgery for bone metastases. Tumor type, performance status, number of bone metastases, visceral metastases, hemoglobin count, and the surgeon's estimate of survival were predictors of patient survival. Our results showed an association of age and comorbidity status with survival. These prognostic factors, in addition to those already known, should be considered when estimating life expectancy. Estimated survival is an important factor in the decision to operate and the selection of operative strategy in patients with metastatic bone disease [2, 13, 18]. Future studies should incorporate these factors in prognostication models to improve prediction accuracy.

We found that exposure to perioperative allogeneic blood transfusion does not decrease survival with the numbers available. However, our sample size might have been insufficient to reveal a small but potentially relevant effect. Our results do suggest a dose-response relationship; patients who received more transfusions had lower survival compared with those with fewer transfusions. Risk of death increased by $7 \%$ per unit of blood transfused.

\section{References}

1. Amato A, Pescatori M. Perioperative blood transfusions for the recurrence of colorectal cancer. Cochrane Database Syst Rev. 2006:CD005033.

2. Bauer HC, Wedin R. Survival after surgery for spinal and extremity metastases: prognostication in 241 patients. Acta Orthop Scand. 1995;66:143-146.

3. Bickels J, Dadia S, Lidar Z. Surgical management of metastatic bone disease. J Bone Joint Surg Am. 2009;91:1503-1516.
4. Buddeberg F, Schimmer BB, Spahn DR. Transfusion-transmissible infections and transfusion-related immunomodulation. Best Pract Res Clin Anaesthesiol. 2008;22:503-517.

5. Capanna R, Campanacci DA. The treatment of metastases in the appendicular skeleton. J Bone Joint Surg Br. 2001;83:471-481.

6. Charlson ME, Pompei P, Ales KL, MacKenzie CR. A new method of classifying prognostic comorbidity in longitudinal studies: development and validation. J Chronic Dis. 1987;40:373-383.

7. Clausen C, Lonn L, Morgen SS, Nielsen MB, Frevert SC, Johansson PI, Dahl B. Perioperative blood transfusion does not decrease survival after surgical treatment of spinal metastases. Eur Spine J. 2014;23:1791-1796.

8. Coleman RE. Clinical features of metastatic bone disease and risk of skeletal morbidity. Clin Cancer Res. 2006;12:6243s-6249s.

9. Deyo RA, Cherkin DC, Ciol MA. Adapting a clinical comorbidity index for use with ICD-9-CM administrative databases. J Clin Epidemiol. 1992;45:613-619.

10. Gantt CL. Red blood cells for cancer patients. Lancet. 1981;2:363.

11. Heiss MM, Mempel W, Jauch KW, Delanoff C, Mayer G, Mempel M, Eissner HJ, Schildberg FW. Beneficial effect of autologous blood transfusion on infectious complications after colorectal cancer surgery. Lancet. 1993;342:1328-1333.

12. Huntington JT, Butterfield M, Fisher J, Torrent D, Bloomston M. The Social Security Death Index (SSDI) most accurately reflects true survival for older oncology patients. Am J Cancer Res. 2013;3:518-522.

13. Katagiri H, Takahashi M, Wakai K, Sugiura H, Kataoka T, Nakanishi K. Prognostic factors and a scoring system for patients with skeletal metastasis. J Bone Joint Surg Br. 2005;87:698-703.

14. Katoh H, Yamashita K, Kokuba Y, Satoh T, Ozawa H, Hatate K, Ihara A, Nakamura T, Onosato W, Watanabe M. Surgical resection of stage IV colorectal cancer and prognosis. World $J$ Surg. 2008;32:1130-1137.

15. Linder BJ, Frank I, Cheville JC, Tollefson MK, Thompson RH, Tarrell RF, Thapa P, Boorjian SA. The impact of perioperative blood transfusion on cancer recurrence and survival following radical cystectomy. Eur Urol. 2013;63:839-845.

16. Margulis V, Shariat SF, Rapoport Y, Rink M, Sjoberg DD, Tannir NM, Abel EJ, Culp SH, Tamboli P, Wood CG. Development of accurate models for individualized prediction of survival after cytoreductive nephrectomy for metastatic renal cell carcinoma. Eur Urol. 2013;63:947-952.

17. Mundy GR. Metastasis to bone: causes, consequences and therapeutic opportunities. Nat Rev Cancer. 2002;2:584-593.

18. Nathan SS, Healey JH, Mellano D, Hoang B, Lewis I, Morris CD, Athanasian EA, Boland PJ. Survival in patients operated on for pathologic fracture: implications for end-of-life orthopedic care. J Clin Oncol. 2005;23:6072-6082.

19. Opelz G, Sengar DP, Mickey MR, Terasaki PI. Effect of blood transfusions on subsequent kidney transplants. Transplant Proc. 1973;5:253-259.

20. Quan H, Li B, Couris CM, Fushimi K, Graham P, Hider P, Januel JM, Sundararajan V. Updating and validating the Charlson comorbidity index and score for risk adjustment in hospital discharge abstracts using data from 6 countries. Am J Epidemiol. 2011;173:676-682.

21. Quan H, Parsons GA, Ghali WA. Validity of information on comorbidity derived rom ICD-9-CCM administrative data. Med Care. 2002;40:675-685.

22. Quinn RH, Randall RL, Benevenia J, Berven SH, Raskin KA. Contemporary management of metastatic bone disease: tips and tools of the trade for general practitioners. Instr Course Lect. 2014;63:431-441.

23. Uccella S, Ghezzi F, Cromi A, Bogani G, Formenti G, Donadello N, Serati M, Bolis P. Perioperative allogenic blood transfusions 
and the risk of endometrial cancer recurrence. Arch Gynecol Obstet. 2013;287:1009-1016.

24. Voskuijl T, Hageman M, Ring D. Higher Charlson Comorbidity Index Scores are associated with readmission after orthopaedic surgery. Clin Orthop Relat Res. 2014;472:1638-1644.
25. Ward WG, Holsenbeck S, Dorey FJ, Spang J, Howe D. Metastatic disease of the femur: surgical treatment. Clin Orthop Relat Res. 2003;415(suppl):S230-244.

26. Wu HS, Little AG. Perioperative blood transfusions and cancer recurrence. J Clin Oncol. 1988;6:1348-1354. 